\title{
Are we together or not? The temporal interplay of monitoring, physiological arousal and physiological synchrony during a collaborative exam
}

\author{
Jonna Malmberg ${ }^{1}$ (D) Eetu Haataja ${ }^{1} \cdot$ Tapio Seppänen $^{1} \cdot$ Sanna Järvelä ${ }^{1}$
}

Received: 18 January 2019 / Accepted: 30 October 2019 / Published online: 23 November 2019

(C) The Author(s) 2019

\begin{abstract}
The coordination of cognitive and non-cognitive interactive processes contributes to successful collaboration in groups, but it is hard to evidence in computer-supported collaborative learning (CSCL). Monitoring is a metacognitive process that can be an indicator of a student's ability to recognize success or failure in collaboration. This study focuses on how monitoring occurs in CSCL during a collaborative exam situation by examining how individual student contributions to monitoring processes are related to physiological synchrony and physiological arousal in groups. The participants were organized in four groups of three members each, and they wore sensors that measured their physiological activity. The data consist of video recordings from collaborative exam sessions lasting 90 minutes and physiological data captured from each student with Empatica 4.0 sensors. The video data were analyzed using qualitative content analysis to identify monitoring events. Students' physiological arousal was determined through peak detection, and physiological concordance was used as an index for the students' physiological synchrony. The individual and group level analysis investigated arousal and physiological synchrony in concordance with monitoring during the collaborative exam. The results showed that, in each group, each student contributed to joint monitoring. In addition, the monitoring activities exhibited a significant correlation with the arousal, indicating that monitoring events are reflected in physiological arousal. Physiological synchrony occurred within two groups, which experienced difficulties during the collaborative exam, whereas the two groups who had no physiological synchrony did not experience difficulties. It is concluded that physiological synchrony may be a new indicator for recognizing meaningful events in CSCL
\end{abstract}

Keywords Collaboration - Computer-supported collaborative learning · Metacognition · Metacognitive monitoring $\cdot$ Physiological arousal $\cdot$ Physiological synchrony

Jonna Malmberg

jonna.malmberg@oulu.fi

Extended author information available on the last page of the article 


\section{Introduction}

Emerging research in computer supported collaborative learning (CSCL) is increasingly targeting the understanding of learners' interactions within the physical and social environment (Wise and Scwartz 2017). This is because the ways in which people interact result from the coordination of cognitive and non-cognitive processes in situated action and social interaction (Miyake and Kirschner 2014). The regulation of individual student learning (self-regulation), that between peers (co-regulation), and learning collectively in groups (socially shared regulation; Hadwin et al. 2017) contributes to reciprocal collaborative interaction (Järvelä et al. 2016) and progress in their collaborative learning (Malmberg et al. 2017). However, it has been shown that learners need extensive support to be able to regulate their learning during collaboration (Järvelä, Hadwin, Järvenoja, \& Malmberg, 2013; Su et al. 2018; Wang et al. 2017), but it is hard to recognize why and how individuals and groups need support in regulation while they learn (Azevedo, Taub, \& Mudrick, 2017), mostly because of methodological challenges to revealing individual and group level cognitive and non-cognitive processes of collaboration (Ludvigsen et al. 2018). This study explores the possibilities of using continuous data resulting from human physiological signals in the context of collaborative exams. So far, physiological sensors have been heavily used in tracking health (e.g., quality of sleep, level of activity), but we suggest that these physiological sensors can also signal a need for regulated learning in the context of collaboration in terms of physiological arousal and physiological synchrony (Järvelä et al. in press).

\section{Collaborative learning and physiological synchrony}

Collaboration is coordinated, synchronous activity which follows constant attempts to construct and maintain a shared understanding of a problem (Roschelle and Teasley 1995). In the context of collaborative learning, the dynamic and reciprocal adaptation of shared interaction emerges: that is, when individuals in a group are not only working on the same activity at the same time, but are also all "in tune" mentally (Baker 2002; Popov et al. 2017). Therefore, synchronicity between individuals in collaborative learning can also be seen in gazes (Schneider and Pea 2013), joint visual attention (Schneider et al. 2018), and physiology (Ahonen et al. 2018; Gillies et al. 2016).

From the physiological perspective, temporal synchronicity occurs when the physiological processes of two or more individuals are associated (for an extensive review, see Palumbo et al., 2016). For example, similar simultaneous changes in students' physiological signals, such as in electrodermal activity (EDA), can be informative of social interactions or task difficulty (Malmberg et al. 2019; Mønster et al. 2016). From a theoretical perspective, one way to conceptualize temporal synchrony is through the theoretical framework of the socially shared regulation of learning. Shared regulation refers to the building and constructing of joint meaning for a task and the negotiation and exchange of ideas concerning how and in what ways joint goals for the task can be met (Järvelä et al. 2018). It includes strategic and metacognitive control over behaviour, cognition, motivation, and emotion (Hadwin et al. 2011; Hadwin et al. 2017), as well as the monitoring of these constructs of regulated learning in synchrony (Winne and Hadwin 1998; Wolters 2011).

Synchrony, the monitoring of progress over time, and the appropriate distribution of resources to monitor cognition, behaviour, motivation, and emotions are all critical to a group's 
collaborative progress (Järvelä et al. 2016; Volet et al. 2017). Yet, since monitoring in collaborative learning is the result of individual self-regulation, it is difficult to evaluate how mentally synchronized group members truly are. For example, if two members of a threemember group externalize their monitoring processes, does this mean that the third member is not involved in monitoring the group's progress at a mental level? In other words, it is hard to determine with the naked eye whether or how individuals in a group are in synchrony with regard to the same activity when such synchrony is not verbally expressed (Järvelä et al. in press).

Synchrony at a physiological level suggests an observed association (or interdependency) between two or more students' physiological processes. Often these physiological signals reflect the connections between people's continuous measures of autonomic nervous systems (Palumbo et al. 2016). Across multiple streams of research, physiological synchrony has been shown to be informative and aligned with social interactions (Mønster et al. 2016). However, there is little research investigating how physiological signals can elucidate behaviour, cognition, motivation, and emotion in educational settings (Harley et al. 2015; Immordino-Yang and Christodoulou 2014). Since physiological signals are sensitive to contextual changes, they hold the potential to advance empirical research on regulated learning (Azevedo 2015). That is, they can provide information related to cognitive demands and task difficulty and increased attention related to task engagement (Henriques et al. 2013). For example, in the context of collaboration, individual learners' physiological reactions are dependent on and shaped by other learners in the same situation (Gillies et al. 2016; Palumbo et al. 2016).

So far, physiological sensors that measure EDA have not been explored much in the context of collaborative learning. These devices can shed light on physiological reactions and learning processes that are not explicitly stated in existing theoretical frameworks (Azevedo and Gašević in press). Yet, the scarce amount of studies that have used such sensors in the context of collaborative learning are promising, indicating that they can, for example, track learning challenges (Malmberg et al. 2019), predict learning outcomes (Pijeira-Díaz et al. 2018), and indicate sharing among group members in monitoring (Haataja, Malmberg, \& Järvelä, 2018). That is why it is highly appealing to not only investigate what students verbally express in a learning situation, but to also study the synchrony across individual physiological reactions, invisible to normal human observation and underlying these non-verbal expressions.

\section{Collaborative learning and metacognitive monitoring}

Learning in groups is not merely a reflection of individual learners, but is a complex combination of all learners' contributions to the group's collective effort, reciprocal interaction, and joint attention (Barron 2003). Learners in collaborative groups share information, search for meanings and solutions, and maintain a shared understanding of the problem (Iiskala et al. 2011). By metacognitive monitoring, learners compare their learning products generated at any point of the learning process (cognitive level) against the standards or goals set for learning (metacognitive level; Winne and Hadwin 1998). Standards at the metacognitive level include information about learners' understanding of the subject matter and whether the procedures used to accomplish the task correspond to the learning goals (Hacker 1998; Perry and Winne 2006). In other words, when engaging in metacognitive monitoring, learners actively think about their learning and the factors that affect it. 
Metacognitive monitoring enables learners to adjust or change their task perceptions, goals, plans, or strategies (Winne and Hadwin 1998). Metacognitive monitoring does not have a clear position in terms of when it occurs in regulated learning, but it can potentially be activated after each regulated learning phase (Sonnenberg \& Bannert, 2016). For example, Molenaar and Chiu (2014) investigated the effects of metacognitive scaffolds in CSCL. The participants of the study were 54 primary school students, working in groups of three. Their task was to write a report about a foreign country. The groups received two different types of scaffolds via avatar, namely structural, metacognitive, and no scaffolds. The results showed that groups that received metacognitive scaffolds also evidenced more metacognitive activities in their collaboration, but the way metacognitive activities and other activities were sequenced were the same in all conditions. Similar findings were also obtained in Su et al.'s (2018) study. Su et al. (2018) investigated college students' regulation in CSCL. Participants completed wikisupported collaborative reading activities in the context of learning English as a foreign language over a semester. The sequential analysis revealed that high performing groups showed a pattern of content monitoring, organizing, and process monitoring. Lowperforming groups, instead, showed the pattern of organizing after organizing, a sign of limited regulatory skills, pointing out the necessity of adaptive scripts in CSCL that facilitate groups' co- and socially shared regulation of learning.

The problem, however, is that despite metacognitive monitoring being successfully scripted and supported in CSCL, such scripts are not equally effective for all students (Järvelä et al. 2013). There is no doubt that supporting metacognitive monitoring is important in CSCL (see Järvelä et al. 2016), but the problem is that the field still lacks methods that can capture "on the fly" important and invisible acts of metacognitive monitoring, when learners themselves monitor task difficulties at an individual and group level (Järvelä et al. in press). Winne (2017) argues that learners are aware, at the metacognitive level, when things are not going as expected. The problem is that learners do not necessary regulate their learning, but rather continue, despite knowing that things are not going as expected. That is why it is important to recognize "on the fly" important and invisible acts of metacognitive monitoring at individual and group levels (Järvelä et al. in press). If such instances can be recognized, then support for the regulation of learning can be provided "in time."

\section{Physiological arousal and physiological synchrony in collaborative learning}

Metacognitive monitoring in collaborative learning has been investigated mainly by counting interaction frequencies, determining the quality of interactions, using think aloud protocols, and investigating changes in individual contributions as groups progress in their collaboration (e.g., Malmberg et al. 2017; Volet et al. 2017). Recently, new, more unobtrusive measures, such as eye-tracking (Schneider et al. 2018) and physiological measures, along with video data, have been used to investigate collaborative learning interactions (i.e., Haataja et al., 2018). Video provides a relatively non-intrusive means of capturing collaborative interaction but falls short in recording some of the non-verbal behaviour. Physiological arousal and physiological synchrony are potential tools for investigating learners' mental activities (Critchley et al. 2013; Palumbo et al., 2016), such as metacognitive monitoring (Hajcak et al. 2003) and sharing in collaborative learning (Järvelä et al. in press). 
Physiological arousal can be considered to be an activity of the sympathetic nervous system, which can be measured by EDA (electrical properties of the skin based on sweat gland activity; Boucsein 2012), whereas physiological synchrony means an association or interdependence (not necessarily high arousal) in physiological signals (e.g., EDA) between two or more people (Palumbo, 2016). During the past few years, there has been a scarce amount of research that has implemented novel, physiological measures when studying metacognitive monitoring and collaboration (Ahonen et al. 2018; Haataja et al., 2018; Järvelä et al. in press). The potential for using physiological measures is that they provide an unobtrusive data collection method, but at the same time, advance research about collaborative learning and the factors that moderate it (Winne 2019).

The value of measuring physiological arousal lies in its indirect access for cognitive and affective processes (Mandler 1984). For cognitive processes, arousal increases depend on the level of attention (Sharot and Phelps 2004), the cognitive demand related to task difficulty, and the cognitive load (Fairclough et al. 2005), as well as engagement related to increased mental effort (Fritz et al. 2014). Increased mental effort, in particular, can potentially improve performance, especially when the task is complex (Pijeira-Díaz et al. 2018).

Prior research suggests that physiological arousal occurs for monitoring events in individual (Hajcak et al. 2003) and collaborative tasks (Ahonen et al. 2018). For example, Malmberg et al. (2019) found that, specifically in group situations where learners were confused and aroused simultaneously, they expressed the most negative emotions, involving markers of metacognitive monitoring. There is also preliminary evidence suggesting that arousal as a level of activation could contribute to learning outcomes (Pijeira-Díaz et al. 2018).

An emerging body of learning research (e.g., Harley et al. 2015; Harley et al. 2019) have investigated physiological arousal in connection with the arousal dimension of emotion in the traditional circumplex model (Russell 1980), which reflects how physiologically activating the emotion is (Pekrun 2006). Still, many theories of emotion (see e.g., Scherer and Moors 2019) also acknowledge the role of information processing in evoking the physiological arousal and steering function, in terms of how arousal is appraised as an emotion (Schachter and Singer 1962), especially in the context of collaborative learning. This is to say that, through appraisals and interception, physiological arousal can be linked to cognition as well as emotion (Barrett 2017; Critchley \& Garfinkel, 2018).

Taking a step forward, measures of physiological arousal can be used as input signals for calculating physiological synchrony. What makes physiological synchrony an interesting variable for collaborative learning research is that it has been linked to better collaboration outcomes (Palumbo et al., 2016) and shared understanding (Järvelä, Kivikangas, Kätsyri, \& Ravaja, 2014). Ahonen et al. (2018) investigated whether physiological synchrony occurs in signals between students when doing collaborative coding tasks and found EDA to be a potential input signal for evaluating collaborative behaviours in a natural setting. Mønster et al. (2016) explored how physiological synchrony occurs during collaborative task execution, showing that physiological synchrony was related to group tension and negative affect. Concerning monitoring and physiological synchrony in groups, Haataja et al. (2018) explored how physiological synchrony temporally co-occurred with monitoring events and found that, for some of the groups, synchrony was found to have a weak but statistically significant positive relation to the monitoring events. 


\section{Aims}

The aim of this study is to understand how metacognitive monitoring occurs during a collaborative exam situation by examining how individual student contributions to monitoring processes are related to physiological arousal and physiological synchrony in groups. The research questions are the following: (1) How do individuals in a group engage in monitoring their learning process during a collaborative exam situation? (2) How does individual students' monitoring frequency relate to physiological arousal? and 3) How does monitoring occur in situations when there is and is not physiological synchrony between the students?

\section{Methods}

\section{Participants and context}

The study was conducted in the spring of 2016 at the University of Oulu, a teacher training school. The study participants comprised 31 high school students $(23$ males, 8 females) aged 15 to 16 years old. All students were enrolled in an advanced physics course as a voluntary part of their studies. The course included traditional lectures as well as working in CSCL. The course lasted the duration of the school term, comprised a total of 24 lessons, and terminated with a collaborative exam during the final lesson. At the beginning of the course, the students were divided into 10 heterogeneous groups of three ( 9 groups) or four members (1 group) based on their previous grades. The students collaborated in these same groups in each lesson. Due to resource limitations, this study sampled 12 students (four groups), who served as the focus for examination of the collaborative group exam.

The collaborative exam required the students to design and report a physics experiment to determine the refractive index of light for water. The collaborative exam constituted of two parts: first, setting up the experiment, which enabled them to measure the refractive index for water, and reporting a) the calculation and b) how the setup was accomplished. The average time spent on the collaborative exam was 28 min and $55 \mathrm{~s}$ $(\mathrm{Std}=53 \mathrm{~s})$, and all the groups were equally successful in terms of being able to calculate the refractive index of light for water and reporting how the setup was accomplished.

\section{Data collection}

This study collected both observation data from recorded videos of the four groups and physiological data, namely the measures of students' electrodermal activity (EDA).

The observation data consisted of video recordings conducted during the students' collaborative exams. The videos were recorded using the MORE video system, which can simultaneously record 30 speech tracks and 3 video tracks through spherical, $360^{\circ}$ point-of-view cameras. Altogether, the researchers collected $1 \mathrm{~h}, 51 \mathrm{~min}$, and $10 \mathrm{~s}$ of video data.

The physiological data were collected using Empatica E4 (Empatica Inc., Boston, MA) multi-sensor wristbands. The wristband tracked the students' EDA. 


\section{Analysis}

\section{Qualitative content analysis}

This analysis investigates how individual visible utterances related to the monitoring of behaviour, cognition, motivation, and emotions occur as the student groups progress in collaborative tasks. The qualitative content analysis focuses on a collaborative exam situation consisting of $1 \mathrm{~h}, 51 \mathrm{~min}$, and $10 \mathrm{~s}$ of video data from four groups. The collaborative exam was selected, since a) a collaborative exam was considered to be meaningful for students, in terms of it playing a major role in the overall grading of the course and because b) the level of physiological signals was higher during the exam when contrasted with other physics lessons (for more detailed information see Pijeira-Díaz et al. 2018). In addition, focusing on a collaborative exam situation provided a possibility to investigate the qualitative aspects of physiological signals in relation to students' collaborative learning process in multiple ways.

At the first stage of the analysis, all the individual student utterances focusing on monitoring the group's collaborative learning progress were identified from the videotaped learning sessions. At this point, monitoring was defined as the monitoring of one's own or the group's cognition, behaviour, motivation, or emotions (Winne and Hadwin 1998). The individual who engaged in each monitoring utterance was identified. At this phase of the analysis, based on earlier studies (Azevedo and Witherspoon 2009; Schunk 1991; Wolters 2011), it was decided to elaborate on the three areas of monitoring in more detail. Thus, the coding was carried out at the individual student level, and each utterance related to monitoring cognition, behaviour, emotion, and motivation was coded.

To develop the coding scheme further, a single video was coded. The coding was negotiated in terms of a) what was being monitored, b) what was not being monitored, and c) empirical examples of the data. After the coding scheme was negotiated, agreed upon, and fine-tuned, another round was conducted in which two researchers coded the same video again using the created coding scheme to ensure that the coding was clear, understandable, and valid for use in the final coding. Table 1 presents the final coding scheme, including examples from the data. The reliability of the coding was ensured by an independent coder, resulting in $84.95 \%$ agreement and $\mathrm{k}=.74$, indicating good agreement (Fleiss 1981).

During the second stage of the qualitative content analysis, the students that reacted to individual monitoring utterances were identified. The reactions were considered to reflect that the individual student acknowledged what had been monitored. Reactions were either a) silent nodding, b) agreeing on what had been monitored, or b) reacting in some visible way to the monitoring event (e.g., if a student said, "Who is willing to draw this?" a student reacted and took a pen, or to "I have no idea what we are doing," the reaction might have been a shaking of the head).

\section{Determining arousal and physiological synchrony}

The analysis investigated arousal and physiological synchrony in concordance with monitoring and the sequential interplay in monitoring during the collaborative learning process at the individual and group levels. Since the frequency of EDA peaks (rapid increases in EDA values) can be used for indicating arousal when the events unfold over time (Mendes 2009), students' arousal was determined through EDA peak detection (Benedek and Kaernbach 2010a, 2010b). Physiological concordance (Marci et al. 2007) was used as an index for the 
Table 1 Qualitative coding scheme and data examples

\begin{tabular}{|c|c|c|}
\hline Monitoring categories & Empirical indicator & Data examples \\
\hline Behaviour & $\begin{array}{l}\text { Monitoring task-related behaviour, } \\
\text { such as the resources needed for } \\
\text { the task. Monitoring task } \\
\text { progression. }\end{array}$ & $\begin{array}{l}\text { "Do we have all the equipment needed?" } \\
\text { "I wonder if the laser is needed any more." } \\
\text { "Does the book include a chapter about this?" } \\
\text { "How much time do we have left?" } \\
\text { "My network is down again." } \\
\text { "We have done task number one. "We can move } \\
\text { on to number two." } \\
\text { "We still have three tasks to do." }\end{array}$ \\
\hline Cognition & $\begin{array}{l}\text { Monitoring task understanding and } \\
\text { prior knowledge. Monitoring } \\
\text { procedural } \\
\text { knowledge and whether the study } \\
\text { product is correct/in the normal } \\
\text { range. } \\
\text { Monitoring content understanding. }\end{array}$ & $\begin{array}{l}\text { "I'm not sure how we are supposed to do this." } \\
\text { "We at least know from previous lessons that the } \\
\text { speed of light won't change." } \\
\text { "We know these values, but this we are missing." } \\
\text { "I have no idea what I'm now doing." } \\
\text { "I'm not sure what it would be wise to do next." } \\
\text { "How are we supposed to use the formula here?" } \\
\text { "I think we should use the wave motion formula } \\
\text { here." } \\
\text { "Is this result in a reasonable range?" } \\
\text { "Are we still adding something, or do } \\
\text { you think this is ready?" }\end{array}$ \\
\hline $\begin{array}{l}\text { Motivation and } \\
\text { Emotions }\end{array}$ & $\begin{array}{l}\text { Monitoring current trends in } \\
\text { motivation. } \\
\text { Monitoring volition and efficacy. } \\
\text { Monitoring emotional state. }\end{array}$ & $\begin{array}{l}\text { "Who is willing to draw this?" } \\
\text { "Our motivation is on a good track." } \\
\text { "I really would not want to do this." } \\
\text { "I'm so bad at drawing. Who can do this?" } \\
\text { "My feelings are good! Let's start." } \\
\text { "These microphones make me annoyed!" } \\
\text { "This is exciting!" }\end{array}$ \\
\hline
\end{tabular}

students' physiological synchrony. First, visually clear movement artefacts were removed from the EDA signal, and the original values were transformed into standardized Z-scores to make the results for each student more comparable (Ben-Shakhar 1985). Second, the EDA signal was smoothed using an adaptive Gaussian filter, the skin conductance level was differentiated from the signal, and peaks with minimum amplitudes of $0.05 \mu \mathrm{S}$ were detected (Benedek and Kaernbach 2010a, 2010b).

Physiological synchrony was derived for each pair in the group from the beginning until the end of the collaborative exam. Physiological synchrony was quantified using the learners' standardized EDA data and the physiological concordance (PC) index (Marci et al. 2007). The average slope of the EDA signal was determined for each student within a moving 5-s window. The Pearson correlations were then calculated over consecutive, running 15-s windows between the students' EDA slope values. Then, a single session index (SSI) was computed from the ratio of the sum of the positive correlations across the entire learning session divided by the sum of the absolute value of the negative correlations across the session. A natural logarithmic transformation of the resulting index was calculated because of the skew inherent in ratios. The index value of zero reflects equal positive and negative correlations and, therefore, a neutral concordance for the episode.

Since signals can also have the same direction by coincidence, the significance of the synchrony was assessed through Monte Carlo shuffling, which has been applied in previous research with a PC index (Karvonen et al. 2016). This was done by calculating the repeated random concordance by keeping the slope values for the first person in the pair stable and then 
randomly picking up the 15-s Pearson correlation window values from the signal of the other person for each moment. Random single session indexes were calculated as described above and then sorted in ascending order to determine the sequence's $95 \%$ point.

To see the temporal variation in physiological synchrony, a moving window of $120 \mathrm{~s}$ was used (see e.g., Haataja et al., 2018; Slovak, Tennent, Reeves, \& Fitzpatrick, 2014). This was done so that the SSI was calculated for the first $120 \mathrm{~s}$ of the session, and, then, the window was moved one second forward sequentially so that the whole session was covered. The mean value for the group was calculated for each moment. Moments in which the moving window value was above average were taken from the video for more detailed qualitative investigation.

\section{Results}

\section{How do individuals in a group monitor their learning progress during a collaborative exam situation?}

Altogether, the four groups monitored their progress 243 times. The students monitored cognition most frequently $(f=138)$, followed by behaviour $(f=99)$. They monitored motivation and emotions six times collectively. Thus, the students primarily monitored cognition and were less likely to monitor motivation and emotions.

In group 1, the left student was the most active in taking charge of monitoring the group's progress $(f=25,44.64 \%)$ during the collaborative exam (Table 2$)$. The middle student engaged in monitoring the group's progress 20 times $(35.71 \%)$, and the right student monitored the group's progress 11 times (19.64\%). Thus, each group member contributed to monitoring the group's progress.

In group 2, the middle student was the most active in terms of taking charge of monitoring the group's progress $(f=27,52.94 \%)$, followed by the left student $(f=21,41.18 \%)$. The right

Table 2 Occurrence of monitoring events at the group and individual student levels

\begin{tabular}{llllll}
\hline & Monitoring $(f)$ & $\begin{array}{l}\text { Monitoring } \\
\text { Duration (Mean) }\end{array}$ & $\begin{array}{l}\text { Monitoring } \\
\text { Duration (Total) }\end{array}$ & Reacting & EDA Peaks* \\
\hline Left student & 25 & $0: 00: 04$ & $0: 01: 30$ & 20 & 434 \\
Middle student & 20 & $0: 00: 03$ & $0: 01: 06$ & 23 & 403 \\
Right student & 11 & $0: 00: 03$ & $0: 00: 36$ & 20 & 343 \\
Group 1 Total & 56 & $0: 00: 05$ & $0: 03: 12$ & 63 & 1180 \\
Left student & 21 & $0: 00: 05$ & $0: 01: 48$ & 23 & 405 \\
Middle student & 26 & $0: 00: 03$ & $0: 02: 09$ & 24 & 260 \\
Right student & 3 & $0: 00: 10$ & 9 & 118 \\
Group 2 Total & 50 & $0: 00: 04$ & $0: 04: 16$ & 56 & 783 \\
Left student & 39 & $0: 00: 04$ & $0: 02: 34$ & 23 & 601 \\
Middle student & 14 & $0: 00: 04$ & $0: 00: 53$ & 30 & 507 \\
Right student & 12 & & $0: 00: 49$ & 23 & 398 \\
Group 3 Total & 65 & $0: 00: 04$ & $0: 04: 16$ & 46 & 1506 \\
Left student & 23 & $0: 00: 03$ & $0: 01: 20$ & 20 & 493 \\
Middle student & 10 & $0: 00: 05$ & $0: 00: 33$ & 27 & 505 \\
Right student & 38 & & $0: 02: 47$ & 89 & 1415 \\
Group 4 Total & 71 & & $0: 04: 40$ & & \\
\hline
\end{tabular}

*Peaks $>0.05 \mu \mathrm{S}$ 
student contributed to joint monitoring three times, offering only $5.88 \%$ of the group's total contributions. Thus, not all group members participated equally in joint monitoring.

In group 3, the left student was the most active in terms of taking charge of monitoring the group's progress $(f=39,60 \%)$ followed by the middle student $(f=14,21.54 \%)$. The right student contributed to joint monitoring 12 times (18.46\% of the total contributions).

In group 4, the right student was the most active in terms of taking charge of monitoring the group's progress $(f=38,53.52 \%)$, followed by the left student $(f=23,32.39 \%)$. The middle student contributed to joint monitoring 10 times (14.08\% of the total contributions).

\section{How do individual students' monitoring frequencies relate to physiological arousal?}

The frequencies of individual students' EDA peaks (range $=118-601, M=471, S D=126.91$ ) were also calculated and contrasted with the monitoring frequency (Tables 2 ). The results show a significant correlation $(r=.663, p<.005)$ between the students' monitoring activities and EDA peaks, such that the students who were most active in monitoring also had the most EDA peaks. Similarly, the students who were least active in monitoring had the fewest EDA peaks. Thus, monitoring activity was correlated with the number of EDA peaks, whereas there was no significant correlation between EDA peaks and reactivity.

\section{How does monitoring occur in situations when there is and is not physiological synchrony between the students?}

In total, two out of four groups showed physiological synchrony at the session level, whereas two groups did not. (Tables 3)Group 2 evidenced significant physiological synchrony between all the group members (left-middle, middle-right, and right-middle), whereas group 4 showed significant physiological synchrony between the left-middle and middle-right student pairs. However, with group 2, physiological synchrony was negative between the left-right student pair.

Table 3 Physiological synchrony between the student pairs

\begin{tabular}{llc}
\hline Student pairs Group 1 & SSI value & $\mathrm{p}$ \\
\hline Left-middle & -0.034 & 0.6635 \\
Middle-right & -0.146 & 0.0502 \\
Left-right & -0.048 & 0.4902 \\
Group 2 & & $<0.0001^{*}$ \\
Left-middle & 0.311 & $<0.0001^{*}$ \\
Middle-right & 0.342 & $<0.0001^{*}$ \\
Left-right & -0.521 & 0.7895 \\
Group 3 & & 0.4383 \\
Left-Middle & -0.018 & 0.0216 \\
Middle-right & -0.044 & 0.0195 \\
Right-left & -0.153 & $0.0046^{*}$ \\
Group 4 & & $<0.0001^{*}$ \\
Left-middle & 0.151 & 0.201 \\
Middle-right & 0.262 & \\
Right-left & & \\
\hline
\end{tabular}

Student pairs marked with * had significant physiological synchrony 
In order to better understand why there was and was not physiological synchrony during the collaborative exam situation at the session level, a detailed case description of the four groups' monitoring processes is provided. In the case descriptions, the types of metacognitive monitoring activities the students engaged in when the value of the groups' physiological synchrony rose above their session mean value are illustrated. Therefore, these time periods can be considered to include moments in which changes in students' physiological signals were most similar between the group members. The case descriptions explain: a) what preceded physiological synchrony, b) what is happening during physiological synchrony, and c) what is monitored, who is monitoring, and who is reacting to the monitoring. The first two case descriptions illustrate groups that showed session level physiological synchrony, whereas the latter two cases illustrate groups that did not show physiological synchrony at the session level. In Figs. 1, 2, 3, and 4, the highest moments of temporal physiological synchrony are presented. The mean of the whole group's EDA value is presented along the Y axis, whereas the $\mathrm{X}$ axis represents the timing of the occurrence of the mean of the whole group's EDA values.

\section{Physiological synchrony at the session level between all the students}

There were two groups that had significant physiological synchrony for the whole session. To better understand what is happening in detail during those temporal physiological synchrony situations, we provide a qualitative description in terms of a) what type of monitoring is involved within those situations and b) how the group members react to the monitoring. What characterizes the two groups that had significant physiological synchrony for the whole session is that both of these groups struggled in terms of how to determine the refractive index of light for water and how to report the results.

Group 2 evidenced physiological synchrony at the session level between all the students. Altogether, there were 5 events when physiological synchrony was above the mean value for group 2 (Fig. 1).

\section{Time 1: (9.10.21-9.12.40) - Doing the experiment - The wrong answer}

Before synchrony The students are finding out how to calculate the reflexive index of water. They have just gathered all the material needed to perform the experiment, but they are not

Group 2

1

$\begin{array}{llll}2 & 3 & 4 & 5\end{array}$

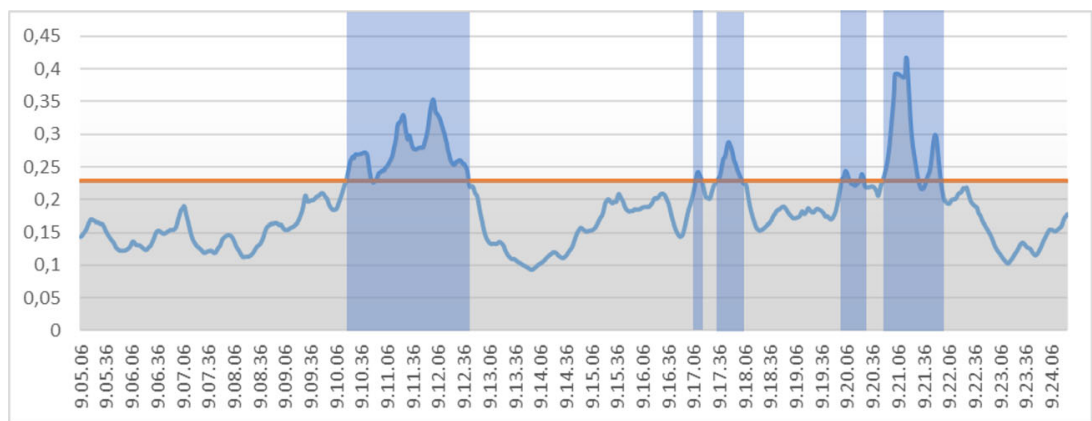

Fig. 1 Group 2. Periods and timing of physiological synchrony 
Group 4

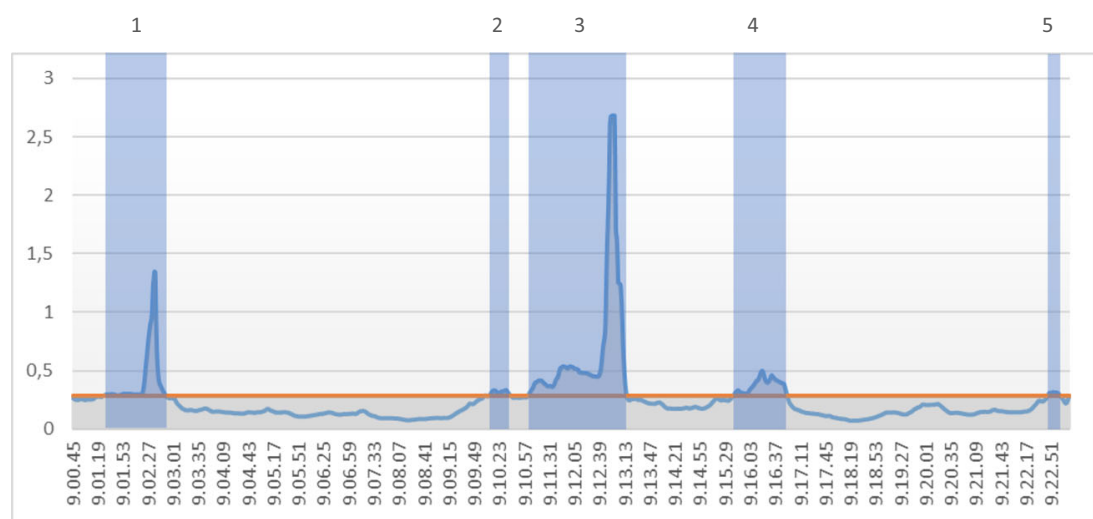

Fig. 2 Group 4. Periods and timing of physiological synchrony

sure how to organize it. Before setting up the experiment, the students are monitoring their progress and asking: "What do we need to do?" "How do we define the refractive index of light for water?" "Do we place it here, or should it go here?" This is to say, before the physiological synchrony, monitoring focuses on monitoring cognition, namely task understanding, and during the physiological synchrony, the monitoring cognition focus shifts to procedural knowledge and whether the study product is correct. Table 4 summarizes what types of monitoring occur during the physiological synchrony at Time 1 .

Time 2: (9.17.09-9.17.14) and time 3: (9.17.38-9.17.59) - Hesitating about the answer

Before synchrony The students are still hesitating about whether their result is accurate enough, stating, "Do we have something wrong with our experiment?" and they have been wondering if they should ask for the teacher's help in terms of confirming whether their result

\section{Group 1}

12

3

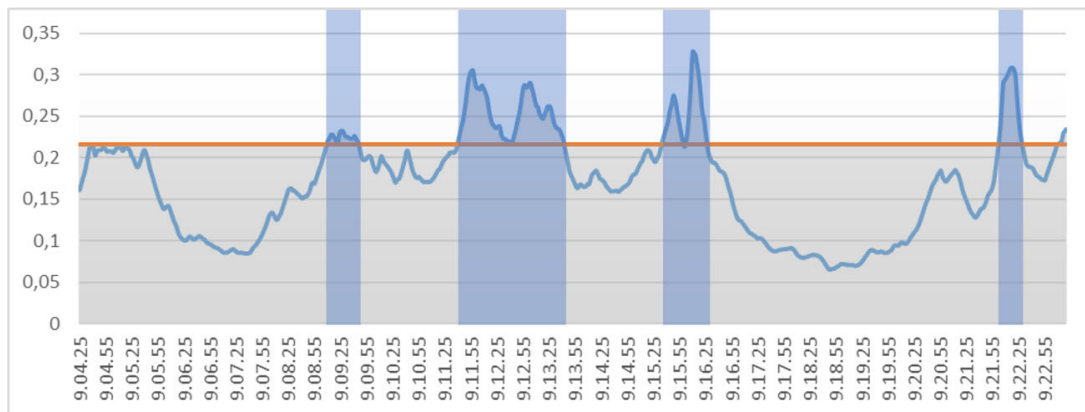

Fig. 3 Group 1. Periods and timing of physiological synchrony 
34

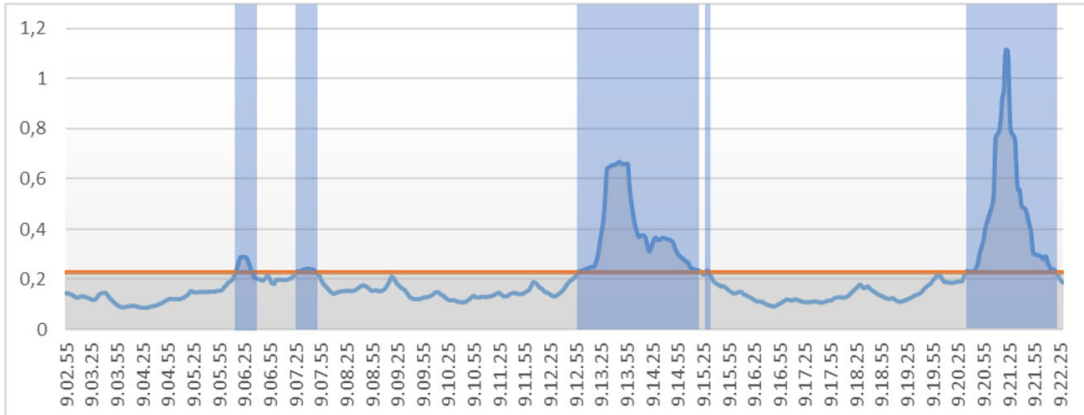

Fig. 4 Group 3. Periods and timing of physiological synchrony

is accurate enough, stating, "Can we ask the teacher if our solution is close enough?" Table 5 summarizes what types of monitoring occur during the physiological synchrony at Times 2 and 3.

\section{Time 4: (9.20.04-9.20.29) and time 5: (9.20.49-9.21.54) - Agreeing on the solution}

Before synchrony The students have almost finalized the task, and they are not confident whether their solution is correct. Table 6 summarizes what types of monitoring occur during the physiological synchrony at Times 4 and 5 .

Table 4 During the synchrony, calculating the reflexive index of water

\begin{tabular}{lllll}
\hline Student Monitoring & $\begin{array}{l}\text { Left } \\
\text { reacting }\end{array}$ & $\begin{array}{l}\text { Middle reacting } \\
\text { reacting }\end{array}$ \\
\hline
\end{tabular}

Right Is this the same from both sides?

$\mathrm{X}$

Right Do we have a calculator?

Right I am not reporting anything yet, let's see how to do that.

Right Should we rotate this?

Right Do we have an eraser?

Right So this gives 45 , times one, well that we don't need, but 45 divided by 60 .

Left But then the refractive index goes down?

Left Is it 30 then?

Right Well, if the normal goes here ...

Middle It is a math error!

Right But it does not show error, not even that minus 1 ?

Middle Well then, it is 0.08 .

Left It is 1.4. What is the exact value?

Left It should be 1.329 .

Middle This is not it ... is this close enough? 
Table 5 During the synchrony, hesitating about the answer

\begin{tabular}{lllll}
\hline Student & Monitoring & Left reacting & Middle reacting & Right reacting \\
\hline Right & How do we even get this number? & $\mathrm{x}$ & $\mathrm{x}$ & $\mathrm{x}$ \\
Middle & $\begin{array}{l}\text { I suppose it is close enough ... } \\
\text { Right }\end{array}$ & $\begin{array}{l}\text { Ok, and next we need to write down } \\
\text { how we came up with our solution. }\end{array}$ & $\mathrm{x}$ & \\
\hline
\end{tabular}

Group 4 evidenced physiological synchrony at the session level between the left- middle and middle-right student pairs. Altogether, there were five episodes when physiological synchrony was above the group mean value of the synchrony (Fig. 2).

\section{Time 1: (9.01.31-9.02.48) - Preparing to do the experiment - Problems with the equipment}

Before synchrony The students are just setting up the equipment needed for the experiment. However, they realize that they have problems in terms of the equipment, and they need to set up their experiment on the floor. Table 7 summarizes what types of monitoring occur during the physiological synchrony at Time 1 .

Time 2: (9.10.13-9.10.33) and Time 3: (9.11.06-9.13.15) - Reporting the experiment How and what?

Before the synchrony The students have reached the solution in terms of calculating the reflexive index of water. Next, they need to report on how they did the experiment; however, they are not sure how they should report the findings and values that they need to report. Table 8 summarizes what types of monitoring occur during the physiological synchrony at Times 2 and 3 .

\section{Time 4: (9.15.43-9.16.50) - What to report?}

Before synchrony The students are still figuring out how they should report their experiment. Also, they express hesitation in terms of how they should report their experiment. Table 9 summarizes what types of monitoring occur during the physiological synchrony at Time 4 .

Table 6 During the synchrony, finalizing the task

\begin{tabular}{|c|c|c|c|c|}
\hline Student & Monitoring & $\begin{array}{l}\text { Left } \\
\text { reacting }\end{array}$ & $\begin{array}{l}\text { Middle } \\
\text { reacting }\end{array}$ & $\begin{array}{l}\text { Right } \\
\text { reacting }\end{array}$ \\
\hline Right & Is there anything else we need to do? & $\mathrm{x}$ & $\mathrm{x}$ & \\
\hline Right & Should we evaluate why our result is not accurate? & $\mathrm{x}$ & $\mathrm{x}$ & \\
\hline Right & $\begin{array}{l}\text { What ...? We were determining the reflexive } \\
\text { index of water here? }\end{array}$ & $\mathrm{x}$ & & \\
\hline Middle & $\begin{array}{l}\text { It is quite accurate. If the value is } .329 \text { and we get } .333 \text { so } \\
\ldots\end{array}$ & $\mathrm{x}$ & & $\mathrm{x}$ \\
\hline
\end{tabular}

Physiological synchrony between left-middle and middle-right students 
Table 7 During the synchrony, preparing to do the experiment

\begin{tabular}{|c|c|c|c|c|}
\hline Student & Monitoring & Left reacting & Middle reacting & Right reacting \\
\hline Right & Where do I have the code? I cannot remember it. & & & \\
\hline Left & Where can we get the water? & & $\mathrm{x}$ & \\
\hline Middle & $\begin{array}{l}\text { Where can we get electricity? On the floor. } \\
\text { Do we need to work on the floor? }\end{array}$ & & & $\mathrm{x}$ \\
\hline Middle & $\begin{array}{l}\text { We need to construct our experiment here, since } \\
\text { we have only limited access to the electricity. }\end{array}$ & $\mathrm{x}$ & & \\
\hline Left & Are there air bubbles in the water or something? & & $\mathrm{x}$ & \\
\hline Middle & $\begin{array}{l}\text { I was wondering how we should place this water? } \\
\text { Well, it doesn't matter. }\end{array}$ & $\mathrm{x}$ & & \\
\hline Left & Ok. What is the task here? I forgot that. & & & \\
\hline
\end{tabular}

\section{Time 5: (9.22.48-9.22.59) - NA}

Despite the fact that there was significant physiological synchrony at Time 5, there were no monitoring events.

No physiological synchrony at the session level.

There were two groups in which group members showed no significant physiological synchrony for the whole session. To better understand what is happening in detail during those temporal physiological synchrony situations, we provide a qualitative description in terms of a) what type of monitoring is involved within those situations and b) how the group members react to the monitoring. What characterizes the two groups that had no significant physiological synchrony for the whole session is that both of these groups expressed that the task was easy.

Group 1 did not evidence physiological synchrony at the session level. However, there were four episodes when physiological synchrony was above the group mean value of the synchrony (Fig. 3).

\section{Time 1: (9.09.14-9.09.44) - Experiment completed}

Before synchrony The students have just calculated the reflective index of water, and they are satisfied with their answer, stating, "Actually, really well invented." Next, they have to report

Table 8 During the synchrony, reporting the results

\begin{tabular}{|c|c|c|c|c|}
\hline Student & Monitoring & $\begin{array}{l}\text { Left } \\
\text { reacting }\end{array}$ & $\begin{array}{l}\text { Middle } \\
\text { reacting }\end{array}$ & $\begin{array}{l}\text { Right } \\
\text { reacting }\end{array}$ \\
\hline Left & Ok, and then the experiment. & & $\mathrm{x}$ & $\mathrm{x}$ \\
\hline Middle & $\begin{array}{l}\text { Do we explain separately how we got the results, } \\
\text { or do we need to explain how we did the } \\
\text { experiment? }\end{array}$ & $\mathrm{x}$ & & $\mathrm{x}$ \\
\hline Left & It has only one reflection or what? & & $\mathrm{x}$ & \\
\hline Left & $\begin{array}{l}\text { But was it necessary to put it there the other } \\
\text { way around? }\end{array}$ & & $\mathrm{x}$ & \\
\hline Left & $\begin{array}{l}\text { What do we write here? What do we say about } \\
\text { our calculations? }\end{array}$ & & $\mathrm{x}$ & \\
\hline Left & $\begin{array}{l}\text { I think we should write down the values separately } \\
\text { for that figure. }\end{array}$ & & $\mathrm{x}$ & \\
\hline
\end{tabular}


Table 9 During the synchrony, reporting the results

\begin{tabular}{|c|c|c|c|c|}
\hline Student & Monitoring & Left reacting & Middle reacting & Right reacting \\
\hline Left & So what exactly are we going to write there? & & $\mathrm{x}$ & \\
\hline Left & $\begin{array}{l}\text { Then, we should probably write down those } \\
\text { values separately. How about that figure? }\end{array}$ & & $\mathrm{x}$ & \\
\hline
\end{tabular}

how they came up with the solution. Table 10 summarizes what types of monitoring occur during the physiological synchrony at Time 1 .

\section{Time 2: (9.11.40-9.13.42) - Reporting the experiment}

Before synchrony The students are starting to write down how they did the experiment and how they got their answer. Table 11 summarizes what types of monitoring occur during the physiological synchrony at Time 2 .

Time 3: (9.15.39-9.16.24) - Checking the solution

Before synchrony The students are reporting how they came up with the solution. They are checking their answer, stating, "We got 1.35, not bad" and "The exact value is 1.31." Also, they are figuring out how to report their solution. Table 12 summarizes what types of monitoring occur during the physiological synchrony at Time 3.

\section{Time 4: 9.22.03-9.22.27 - The task is done}

Before synchrony The students are just finalizing their report, and they express how they have a "good feeling now that we finalized this!" Table 13 summarizes what types of monitoring occur during the physiological synchrony at Time 4.

\section{No physiological synchrony at the session level}

Group 3 did not evidence physiological synchrony at the session level. However, there were five episodes when physiological synchrony was above the group mean value of the synchrony (Fig. 4).

Table 10 During the highest synchrony, finishing the calculation

\begin{tabular}{|c|c|c|c|c|}
\hline Student & Monitoring & Left reacting & Middle reacting & Right reacting \\
\hline Right & $\begin{array}{l}\text { Ok, we have the calculations and all the } \\
\text { subprocesses related to those. } \\
\text { We still need to give an explanation } \\
\text { for our solution. }\end{array}$ & & & \\
\hline Left & Do we also report how we did the experiment? & & & \\
\hline
\end{tabular}


Table 11 During the highest synchrony, reporting the solution

\begin{tabular}{|c|c|c|c|c|}
\hline Student & Monitoring & Left reacting & Middle reacting & Right reacting \\
\hline Middle & What is this? Refraction angle? & & & $\mathrm{x}$ \\
\hline Right & This will be a great answer! & & & \\
\hline Right & $\begin{array}{l}\text { I will take away the water, I will try to } \\
\text { be useful somehow. }\end{array}$ & & & \\
\hline Left & Where was this? & & $\mathrm{x}$ & \\
\hline Middle & $\begin{array}{l}\text { Is the value of the refractive index in the } \\
\text { spreadsheet? I know it is } 1 \text {, but is it there? }\end{array}$ & $\mathrm{x}$ & & \\
\hline
\end{tabular}

\section{Time 1: (9.06.16-9.06.31) and time 2: (9.07.33-9.07.50) - How can this be so easy?}

Before synchrony The students have calculated the refractive index of water and wonder about how easy the task was, stating, "How can this be so easy?" Next, they have to report how they came up with the solution and use the correct terminology. Table 14 summarizes what types of monitoring occur during the physiological synchrony at Times 1 and 2 .

Time 3: (9.13.10-9.15.16) and time 4: (9.15.29-9.15.31) - Checking the solution

Before synchrony The students are checking whether the formula they used is correct. Table 15 summarizes what types of monitoring occur during the physiological synchrony at Times 3 and 4 .

Time 5: (9.20.35-9.22.19) - How can this be so easy?

Before synchrony The students have finalized the task, and they have come to the conclusion that the task was easy. Table 16 summarizes what types of monitoring occur during the physiological synchrony at Time 5 .

To conclude, the two groups that had significant physiological synchrony during the whole session struggled with the task by expressing hesitation in terms of their task solution, and the two groups who had no significant physiological synchrony for the whole session were more confident in terms of their task solution.

Table 12 During the highest synchrony, reporting the solution

\begin{tabular}{lllll}
\hline Student & Monitoring & $\begin{array}{l}\text { Left } \\
\text { reacting }\end{array}$ & $\begin{array}{l}\text { Middle } \\
\text { reacting }\end{array}$ & $\begin{array}{l}\text { Right } \\
\text { reacting }\end{array}$ \\
\hline $\begin{array}{l}\text { Right } \\
\text { Right }\end{array}$ & What was the value in the spreadsheet? & $\mathrm{x}$ & & \\
$\begin{array}{l}\text { Middle } \\
\text { Left }\end{array}$ & Ok, and then the explanation. How do we explain this? & x & & $\mathrm{x}$ \\
Middle & Look, if we added this, then it would be like this. & $\mathrm{x}$ & $\mathrm{x}$ & $\mathrm{x}$ \\
\hline
\end{tabular}


Table 13 During the highest synchrony, checking the solution

\begin{tabular}{|c|c|c|c|c|}
\hline Student & Monitoring & Left reacting & Middle reacting & Right reacting \\
\hline Left & Do we need other explanations? & & & \\
\hline Right & Are our names there? & & $\mathrm{x}$ & \\
\hline Left & Good feeling now when we finished that! & & $\mathrm{x}$ & \\
\hline
\end{tabular}

\section{Discussion}

The study investigated how metacognitive monitoring, physiological arousal, and physiological synchrony occur during a collaborative exam situation in a CSCL context. Specifically, it first examined individual contributions to monitoring processes and the related physiological arousal. Second, it investigated how monitoring processes and physiological synchrony occur simultaneously during collaborative learning.

The results showed that, in each group, each student contributed to joint monitoring. In addition, the monitoring activities exhibited significant correlation with the EDA peaks, suggesting that monitoring activities might be reflected in such peaks. Earlier research has shown that peaks in EDA can reflect students' appraisals of task difficulty (Pecchinenda and Smith 1996). In the current study, task difficulty was not measured, but rather how students monitor their progress. Thus, this monitoring compares features of the current state of learning to those of the desired state (Winne 2011), which allows learners to compare learning products against the desired learning goals. Results are also in line with the theory suggesting that physiological arousal measured from EDA peaks can, on some level, reflect how active the students are in their learning process (Pijeira-Díaz et al. 2018). In this study, there was a correlation between monitoring and physiological arousal, which is in line with earlier studies, suggesting that physiological arousal reacts to monitoring events (Hajcak et al. 2003). It can also be explained by the fact that monitoring is a process, which makes the students aware of the need to change the current state of learning, and, therefore, physiological arousal reflecting action tendency might also react to this need.

The results showed no straightforward connection between monitoring events and physiological synchrony. One group had significant SSIs between all group members at the session level. One group had significant physiological synchrony between two pairs inside the group at the session level. Finally, two groups had no significant physiological synchrony at the session level. More detailed qualitative analysis about what types of monitoring activities precede temporal synchrony situations and about what types of monitoring events occur during temporal synchrony situations indicate that the groups that had significant physiological synchrony at the session level also expressed more difficulties in terms of the collaborative exam. This finding is aligned with earlier studies indicating that physiological synchrony is correlated with group tension and negative expressions (Mønster et al. 2016), and might be explained by the fact that when difficulties in collaborative learning are confronted, it is also

Table 14 During the highest synchrony, reporting the solution

\begin{tabular}{|c|c|c|c|c|}
\hline Student & Monitoring & Left reacting & Middle reacting & Right reacting \\
\hline Right & Wait a minute - was it called a refraction angle? & & $\mathrm{x}$ & \\
\hline Left & Ok, and then we just need to calculate that ... & & & \\
\hline Right & Isn't that just sin alpha 1 divided by $\sin$ alpha 2 ? & & & \\
\hline
\end{tabular}


Table 15 During the highest synchrony, checking the solution

\begin{tabular}{lllll}
\hline Student & Monitoring & $\begin{array}{l}\text { Left } \\
\text { reacting }\end{array}$ & $\begin{array}{l}\text { Middle } \\
\text { reacting }\end{array}$ & $\begin{array}{l}\text { Right } \\
\text { reacting }\end{array}$ \\
\hline Right & $\begin{array}{l}\text { The formula for the refraction angle is also here (points to } \\
\text { the book). }\end{array}$ & \\
\end{tabular}

reflected in physiological synchrony at the session level. In contrast, when the task is not difficult, learners are not in synchrony. Similar findings were also obtained in Haataja et al.'s (2018) study, which studied metacognitive monitoring and physiological synchrony in CSCL. Recently, Dindar et al. (2019) studied how similarity in students' cognitive evaluations was reflected in EDA measures during collaborative learning. They found that students who had concordant metacognitive evaluations about their task-related knowledge also showed more physiological synchrony. In light of these studies, it can be argued that physiological synchrony may be informative in terms of exploring monitoring during collaborative learning, especially when monitoring involves markers of difficulties.

In addition, learners' reactions to metacognitive monitoring were not reflected in EDA or physiological synchrony. This can be due to two reasons. First, it can be concluded that EDA, in general, is more sensitive to anticipation and cognitive work (Critchley 2002), but reaction can also be passive and, therefore, is not reflected in EDA. Second, this study focused only on metacognitive monitoring and not whether it followed the regulation of learning. In the future, there is also a need to recognize situations that involve metacognitive monitoring following the socially shared regulation of learning. This, however, is not easy. For example, earlier work (Malmberg et al. 2019) investigated the types of interaction that occurred during simultaneous high arousal segments in the context of collaboration. The interaction types during simultaneous arousal segments were considered either high- or low-level interaction. The results showed that most of the collaborative interaction during simultaneous arousal segments was low-level (Volet, Vauras \& Salonen, 2009), and regulated learning was not observable. However, during high-level interaction segments, the regulation of learning and, specifically, metacognitive monitoring was found. Nevertheless, a straightforward connection between simultaneous arousal and the regulation of learning was not found.

Despite the fact that empirical research on physiological data and relevant learning processes is still in its infancy, the findings of this study can give cautious suggestions for further studies. First, monitoring events are reflected in physiological arousal. This is to say that physiological arousal is informative of learning-oriented activity. It can signal whether or not learners are mentally engaged towards solving complex tasks. Second, physiological synchrony was not related to the easiness of the task, but rather, it informed about difficulties. It might be that the challenges that invite students together to monitor and regulate also evoke synchrony between them. This is to say that physiological synchrony can reflect joint cognitive and affective coordination of behaviours and affective states between individuals interacting in a social setting (Hernandez et al. 2014). However, some of these early results are incoherent, and more research is needed to draw a clearer picture of the phenomena in relation to regulation in

Table 16 During the highest synchrony, an "easy task"

\begin{tabular}{lllll}
\hline Student & Monitoring & Left reacting & Middle reacting & Right reacting \\
\hline Left & But how can this be so easy? & x & x \\
\hline
\end{tabular}


collaborative learning. Despite the exploratory nature of this study, the results align with those of previous studies (Dindar et al. 2017; Haataja et al., 2018; Järvelä et al. in press; Malmberg et al. 2019). This study suggests that the use of physiological data in triangulation with other data (e.g., video) has the potential to uncover otherwise unidentifiable psychophysiological reactions and accompanying social and contextual processes related to collaborative learning.

\section{Conclusion and practical implications}

In this study, collaborative learning was considered through regulatory mechanisms that promote collaborative knowledge construction (Järvelä et al. in press). According to theoretical models of self-regulated learning (Hadwin et al. 2017; Winne and Hadwin 1998), first, a need for regulation should be recognized through a) metacognitive monitoring and, second, group level interaction that focuses on b) the regulation of learning that is relevant for optimizing cognitive, motivational, and emotional aspects of regulation. Yet, the challenge is that, despite the conceptualization of regulated learning, we still lack efficient methods and techniques to recognize events of the self-regulation or socially shared regulation of learning. So far, the methods that have been able to reach the regulation of learning in CSCL have mainly focused on analyzing video data or written text, which is labour intensive to analyze (see Wang \& Hong, 2018), and this was also the case in this study. Due to the small size and qualitative nature of these findings, it is not possible to generalize them. In the future, perhaps new methods, such as speech recognition or natural language processing (NLP), will have the capability to at least ease the process of finding the meaningful events in CSCL (see e.g., Spikol et al. 2018). Another less laborious approach would be connecting physiological data with logfile traces that capture student interaction. That type of approach could provide possibilities for gathering big data and analyzing and interpreting learners' observed behaviour and related physiological reactions both at the individual and group levels. If we are able to collect big and comprehensive data that also integrate physiological signals, we could make generalizations about the meaning of physiological signals and develop the field of CSCL further (Wise and Scwartz 2017). The advantage of using physiological sensors in the data collection is that they are "seamless," and they record bodily reactions "on the fly" that shed light on the mental reactions of individuals and groups. Therefore, more research that has explanatory power is required to further explore and understand the interplay between metacognition, regulation, and physiological signals.

The results contribute to the field of CSCL for three reasons. First, the alignment of monitoring is necessary for socially shared regulation (Hadwin et al. 2017; Malmberg et al., 2016), which is needed for effective collaboration. Second, this study seeks to reveal if and why individuals in a group are physiologically in synchrony with the same activity if such synchrony cannot be observed in verbal interactions. In CSCL, synchronicity has the potential to reveal whether individuals in a group are attuned towards the same mental activity (Popov et al. 2017). Third, this study contributes methodologically to the field of CSCL by taking advantage of physiological data that have not yet been explored much. Eventually, the methods used in this study could be developed further in order to design a computational model capable of automatically detecting (Gašević et al. 2018) students' metacognitive activity as indicators for difficulties that arise in collaborative learning. As Ludvigsen (2016) pointed out, more interdisciplinary research is needed to advance the development of CSCL in the future.

Funding Information Open access funding provided by University of Oulu including Oulu University Hospital. 
Open Access This article is distributed under the terms of the Creative Commons Attribution 4.0 International License (http://creativecommons.org/licenses/by/4.0/), which permits unrestricted use, distribution, and reproduction in any medium, provided you give appropriate credit to the original author(s) and the source, provide a link to the Creative Commons license, and indicate if changes were made.

\section{References}

Ahonen, L., Cowley, B. U., Hellas, A., \& Puolamäki, K. (2018). Biosignals reflect pair-dynamics in collaborative work: EDA and ECG study of pair-programming in a classroom environment. Scientific Reports, 8(1), 3138. https://doi.org/10.1038/s41598-018-21518-3.

Azevedo, R. (2015). Defining and measuring engagement and learning in science: Conceptual, theoretical, methodological, and analytical issues. Educational Psychologist, 50(1), 84-94. https://doi.org/10.1080 $/ 00461520.2015 .1004069$.

Azevedo, R., \& Witherspoon, A. M. (2009). Self-regulated learning with hypermedia. In D. J. Hacker, J. Dunlosky, \& A. C. Graesser (Eds.), Handbook of metacognition in education (pp. 319-339). New York: Routledge.

Azevedo, R., Taub, M., \& Mudrick, N. V. (2017). Understanding and reasoning about real-time cognitive, affective, and metacognitive processes to foster self-regulation with advanced learning technologies. In D. Schunk \& J. A. Greene (Eds.), Handbook of self-regulation and performance (2nd ed.). New York: Routledge.

Baker, M. (2002). Argumentative interactions, discursive operations and learning to model in science. In P. Brna, M. Baker, \& K. Stenning (Eds.), The role of communication in learning to model (pp. 303-324). Lawrence Erlbaum Associates.

Barrett, L. F. (2017). The theory of constructed emotion: An active inference account of interception and categorization. Social Cognitive and Affective Neuroscience, 12(1), 1-23.

Barron, B. (2003). When smart groups fail. Journal of the Learning Sciences, 12(3), 307-359. https://doi. org/10.1207/S15327809JLS1203 1.

Benedek, M., \& Kaernbach, C. (2010a). A continuous measure of phasic electrodermal activity. Journal of Neuroscience Methods, 190(1), 80-91. https://doi.org/10.1016/j.jneumeth.2010.04.028.

Benedek, M., \& Kaernbach, C. (2010b). Decomposition of skin conductance data by means of nonnegative deconvolution. Psychophysiology, 47(4), 647-658. https://doi.org/10.1111/j.1469-8986.2009.00972.x.

Ben-Shakhar, G. (1985). Standardization within individuals: A simple method to neutralize individual differences in skin conductance. Psychophysiology, 22(3), 292-299. https://doi.org/10.1111/j.1469-8986.1985.tb01603.x.

Boucsein, W. (2012). Electrodermal activity (2nd ed.). New York: Springer.

Critchley, H. D. (2002). Electrodermal responses: What happens in the brain. Neuroscientist, 8, $132-142$. https://doi.org/10.1177/107385840200800209.

Critchley, H. D., Eccles, J., \& Garfinkel, S. N. (2013). Interaction between cognition, emotion, and the autonomic nervous system. Handbook of Clinical Neurology, 117(October), 59-77. https://doi.org/10.1016/B978-0444-53491-0.00006-7.

Critchley, H. D., \& Garfinkel, S. N. (2018). The influence of physiological signals on cognition. Current Opinion in Behavioral Sciences, 19, 13-18.

Dindar, M., Malmberg, J., Järvelä, S., Haataja, E., \& Kirschner, P.A. (2017). Matching self-reports with electrodermal activity data: Investigating temporal changes in self-regulated learning. Manuscript in preparation.

Dindar, M., Alikhani, I., Malmberg, J., Järvelä, S., \& Seppänen, T. (2019). Examining shared monitoring in collaborative learning: A case of a recurrence quantification analysis approach. Computers in Human Behavior.

Fairclough, S. H., Venables, L., \& Tattersall, A. (2005). The influence of task demand and learning on the psychophysiological response. International Journal of Psychophysiology, 56(2), 171-184.

Fleiss, J. (1981). Statistical examples for rates and proportions. New York: John Wiley.

Fritz, T., Begel, A., Müller, S.C., Yigit-Elliott, S., \& Züger, M. (2014). Using psycho-physiological measures to assess task difficulty in software development. Proceedings of the 36th International Conference on Software Engineering - ICSE 2014 (pp. 402-413). New York: ACM Press. https://doi.org/10.1145 /2568225.2568266.

Gašević, D., Joksimović, S., Eagan, B. R., \& Shaffer, D. W. (2018). SENS: Network analytics to combine social and cognitive perspectives of collaborative learning. Computers in Human Behavior, 92, 562-577.

Gillies, R. M., Carroll, A., Cunnington, R., Rafter, M., Palghat, K., Bednark, J., \& Bourgeois, A. (2016). Multimodal representations during an inquiry problem-solving activity in a year 6 science class: A case study investigating cooperation, physiological arousal and belief states. Australian Journal of Education, 60(2), 111-127. https://doi.org/10.1177/0004944116650701. 
Haataja, E., Malmberg, J., \& Järvelä, S. (2018). Monitoring in collaborative learning: Co-occurrence of observed behavior and physiological synchrony explored. Computers in Human Behavior, 87, 337-347.e

Hacker, D. J. (1998). Definitions and empirical foundations. In D. J. Hacker, J. Dunlosky, \& A. C. Graesser (Eds.), Metacognition in educational theory and practice (pp. 1-23). Mahwah: Routledge.

Hadwin, A. F., Järvelä, S., \& Miller, M. (2011). Self-regulated, co-regulated, and socially shared regulation of learning. In B. J. Zimmerman \& D. H. Schunk (Eds.), Handbook of self-regulation of learning and performance (pp. 65-86). New York: Routledge.

Hadwin, A.F., Järvelä, S., \& Miller, M. (2017). Self-regulation, co-regulation and shared regulation in collaborative learning environments. Manuscript in preparation.

Hajcak, G., McDonald, N., \& Simons, R. F. (2003). To err is autonomic: Error-related brain potentials, ANS activity, and post-error compensatory behavior. Psychophysiology, 40(6), 895-903. https://doi.org/10.1111 /1469-8986.00107.

Harley, J. M., Bouchet, F., Hussain, M. S., Azevedo, R., \& Calvo, R. (2015). A multi-componential analysis of emotions during complex learning with an intelligent multi-agent system. Computers in Human Behavior, 48, 615-625. https://doi.org/10.1016/j.chb.2015.02.013.

Harley, J. M., Jarrell, A., \& Lajoie, S. P. (2019). Emotion regulation tendencies, achievement emotions, and physiological arousal in a medical diagnostic reasoning simulation. Instructional Science, 1-30.

Henriques, R., Paiva, A., \& Antunes, C. (2013). On the need of new methods to mine electrodermal activity in emotion-centered studies. In L. Cao, Y. Zeng, A. L. Symeonidis, V. I. Gorodetsky, P. S. Yu, \& M. P. Singh (Eds.), Agents and data mining interaction (Vol. 7607, pp. 203-215). Berlin: Springer. https://doi. org/10.1007/978-3-642-36288-0_18.

Hernandez, J., Riobo, I., Rozga, A., Ābowd, G., \& Picard, R. (2014). Using electrodermal activity to recognize ease of engagement in children during social interactions. UbiComp 2014 - Proceedings of the 2014 ACM International Joint Conference on Pervasive and Ubiquitous Computing. https://doi.org/10.1145 /2632048.2636065.

Iiskala, T., Vauras, M., Lehtinen, E., \& Salonen, P. (2011). Socially shared metacognition of dyads of pupils in collaborative mathematical problem-solving processes. Learning and Instruction, 21(3), 379-393. https://doi.org/10.1016/j.learninstruc.2010.05.002.

Immordino-Yang, M. H., \& Christodoulou, J. A. (2014). Neuroscientific contributions to understanding and measuring emotions in educational contexts. In R. Pekrun \& L. Linnenbrink (Eds.), International handbook of emotions in education (pp. 617-625). Routledge. https://doi.org/10.4324 /9780203148211.ch30.

Järvelä, S., Järvenoja, H., Malmberg, J., \& Hadwin, A. F. (2013). Exploring socially shared regulation in the context of collaboration. Journal of Cognitive Education and Psychology, 12(3), 267-286.

Järvelä, S., Kivikangas, J. M., Kätsyri, J., \& Ravaja, N. (2014). Physiological linkage of dyadic gaming experience. Simulation \& Gaming, 45(1), 24-40.

Järvelä, S., Malmberg, J., \& Koivuniemi, M. (2016). Recognizing socially shared regulation by using the temporal sequences of online chat and logs in CSCL. Learning and Instruction, 42, 1-11. https://doi. org/10.1016/j.learninstruc.2015.10.006.

Järvelä, S., Hadwin, A. F., Malmberg, J., \& Miller, M. (2018). Contemporary perspectives of regulated learning in collaboration. In F. Fischer, C. E. Hmelo-Silver, P. Reimann, \& S. R. Goldman (Eds.), Handbook of the learning sciences (pp. 127-136). New York: Routledge.

Järvelä, S., Malmberg, J., Sobocinski, M., Haataja, E., \& Kirschner, P. A. (in press). What multimodal data can tell us about the self-regulated learning process? Learning and Instruction.

Karvonen, A., Kykyri, V.-L., Kaartinen, J., Penttonen, M., \& Seikkula, J. (2016). Sympathetic nervous system synchrony in couple therapy. Journal of Marital and Family Therapy, 42(3), 383-395. https://doi. org/10.1111/jmft.12152.

Ludvigsen, S. (2016). CSCL towards the future: The second decade of ijCSCL. International Journal of Computer-Supported Collaborative Learning, 11(1), 1-7.

Ludvigsen, S., Cress, U., Rosé, C. P., Law, N., \& Stahl, G. (2018). Developing understanding beyond the given knowledge and new methodologies for analyses in CSCL. International Journal of Computer-Supported Collaborative Learning, 13(1), 1-6.

Malmberg, J., Järvelä, S., \& Järvenoja, H. (2017). Capturing temporal and sequential patterns of self-, co-, and socially shared regulation in the context of collaborative learning. Contemporary Educational Psychology, 49, 160-174. https://doi.org/10.1016/j.cedpsych.2017.01.009.

Malmberg, J., Järvelä, S., Holappa, J., Haataja, E., Huang, X., \& Siipo, A. (2019). Going beyond what is visible: What multichannel data can reveal about interaction in the context of collaborative learning? Computers in Human Behavior, 96, 235-245. 
Mandler, G. (1984). Mind and body: Psychology of emotion and stress. New York: Norton \& Company.

Marci, C. D., Ham, J., Moran, E., \& Orr, S. P. (2007). Physiologic correlates of perceived therapist empathy and social-emotional process during psychotherapy. The Journal of Nervous and Mental Disease, 195(2), 103111. https://doi.org/10.1097/01.nmd.0000253731.71025.fc.

Mendes, W. B. (2009). Assessing autonomic nervous system activity. In E. Harmon-Jones \& J. S. Beer (Eds.), Methods in social neuroscience (pp. 118-147). New York: Guilford Press.

Miyake, N., \& Kirschner, P. A. (2014). The social and interactive dimensions of collaborative learning. In K. R. Sawyer (Ed.), The Cambridge handbook of the learning sciences (pp. 418-438). New York: Cambridge University Press.

Molenaar, I., \& Chiu, M. M. (2014). Dissecting sequences of regulation and cognition: Statistical discourse analysis of primary school children's collaborative learning. Metacognition and Learning, 9(2), 137-160. https://doi.org/10.1007/s11409-013-9105-8.

Mønster, D., Håkonsson, D. D., Eskildsen, J. K., \& Wallot, S. (2016). Physiological evidence of interpersonal dynamics in a cooperative production task. Physiology and Behavior, 156, 24-34. https://doi.org/10.1016/j. physbeh.2016.01.004.

Palumbo, R. V., Marraccini, M. E., Weyandt, L. L., Wilder-Smith, O., McGee, H. A., Liu, S., \& Goodwin, M. S. (2016). Interpersonal autonomic physiology: A systematic review of the literature. Personality and Social Psychology Review, 21(2), 99-141. https://doi.org/10.1177/1088868316628405.

Pecchinenda, A., \& Smith, C. (1996). The affective significance of skin conductance activity during a difficult problem-solving task. Cognition and Emotion, 10(5), 481-503. https://doi.org/10.1080/026999396380123.

Pekrun, R. (2006). The control-value theory of achievement emotions: Assumptions, corollaries, and implications for educational research and practice. Educational Psychology Review, 18, 315-341. https://doi. org/10.1007/s10648-006-9029-9.

Perry, N. E., \& Winne, P. H. (2006). Learning from learning kits: Study traces of students' self-regulated engagements with computerized content. Educational Psychology Review, 18(3), 211-228. https://oi. org/10.1007/s10648-006-9014-3.

Pijeira-Díaz, H.J., Drachsler, H., Kirschner, P.A., \& Järvelä, S. (2018). Profiling sympathetic arousal in a physics course: How active are students? Journal of Computer Assisted Learning, (April), 1-12. https://doi.org/10.1111/jcal.12271.

Popov, V., van Leeuwen, A., \& Buis, S. C. A. (2017). Are you with me or not? Temporal synchronicity and transactivity during CSCL. Journal of Computer Assisted Learning, 1-19. https://doi.org/10.1111/jcal.12185.

Roschelle, J., \& Teasley, S. (1995). The construction of shared knowledge in collaborative problem solving. In C. O’Malley (Ed.), Computer supported collaborative learning (Vol. 128, pp. 69-97). Springer Berlin Heidelberg. https://doi.org/10.1007/978-3-642-85098-1_5.

Russell, J. A. (1980). A circumplex model of affect. Journal of Personality and Social Psychology, 39(6), 11611178. https://doi.org/10.1037/h0077714.

Schachter, S., \& Singer, J. (1962). Cognitive, social, and physiological determinants of emotional state. Psychological Review, 69(5), 379-399. https://doi.org/10.1037/h0046234.

Scherer, K. R., \& Moors, A. (2019). The emotion process: Event appraisal and component differentiation. Annual Review of Psychology, 70(1), 719-745. https://doi.org/10.1146/annurev-psych-122216-011854.

Schneider, B., \& Pea, R. (2013). Real-time mutual gaze perception enhances collaborative learning and collaboration quality. International Journal of Computer-Supported Collaborative Learning, 8(4), 375397. https://doi.org/10.1007/s11412-013-9181-4.

Schneider, B., Sharma, K., Cuendet, S., Zufferey, G., Dillenbourg, P., \& Pea, R. (2018). Leveraging mobile eyetrackers to capture joint visual attention in co-located collaborative learning groups. International Journal of Computer-Supported Collaborative Learning, 241-261. https://doi.org/10.1007/s11412-018-9281-2.

Schunk, D. H. (1991). Self-efficacy and academic motivation. Educational Psychologist, 26(3-4), $207-231$. https://doi.org/10.1080/00461520.1991.9653133.

Sharot, T., \& Phelps, E. A. (2004). How arousal modulates memory: Disentangling the effects of attention and retention. Cognitive, Affective, \& Behavioral Neuroscience, 4(3), 294-306. https://doi.org/10.3758 /CABN.4.3.294.

Slovák, P., Tennent, P., Reeves, S., \& Fitzpatrick, G. (2014). Exploring skin conductance synchronisation in everyday interactions. NordiCHI'14 (pp. 511-520).

Sonnenberg, C., \& Bannert, M. (2016). Evaluating the impact of instructional support using data mining and process mining: A micro-level analysis of the effectiveness of metacognitive prompts. Journal of Educational Data Mining, 8(2), 51-83.

Spikol, D., Ruffaldi, E., Dabisias, G., \& Cukurova, M. (2018). Supervised machine learning in multimodal learning analytics for estimating success in project-based learning, (march), 366-377. https://doi. org/10.1111/jcal.12263.

Su, Y., Li, Y., Hu, H., \& Rosé, C. P. (2018). Exploring college English language learners' self and social regulation of learning during wiki-supported collaborative reading activities. International Journal of Computer-Supported Collaborative Learning, 1-26. https://doi.org/10.1007/s11412-018-9269-y. 
Volet, S., Vauras, M., Salo, A.-E., \& Khosa, D. (2017). Individual contributions in student-led collaborative learning: Insights from two analytical approaches to explain the quality of group outcome. Learning and Individual Differences, 53, 79-92. https://doi.org/10.1016/j.lindif.2016.11.006.

Volet, S., Vauras, M., \& Salonen, P. (2009). Self-and social regulation in learning contexts: An integrative perspective. Educational psychologist, 44(4), 215-226.

Wang, S. L., \& Hong, H. T. (2018). The roles of collective task value and collaborative behaviors in collaborative performance through collaborative creation in CSCL. Educational Technology Research and Development, 66(4), 937-953.

Wang, X., Kollar, I., \& Stegmann, K. (2017). Adaptable scripting to foster regulation processes and skills in computer-supported collaborative learning. International Journal of Computer-Supported Collaborative Learning, 12(2), 153-172. https://doi.org/10.1007/s11412-017-9254-x.

Winne, P. H. (2017). Cognition and metacognition within self-regulated learning. In Handbook of self-regulation of learning and performance (pp. 52-64). In D. Schunk, \& J. Greene (Eds.). Handbook of self-regulation of learning and performance(2nd ed.). New York, NY: Routledge.Routledge.

Winne, P. H. (2019). Paradigmatic dimensions of instrumentation and analytic methods in research on selfregulated learning. Computers in Human Behavior, 96, 285-289.

Winne, P. H., \& Hadwin, A. F. (1998). Studying as self-regulated learning. In D. J. Hacker, J. Dunlosky, \& A. C. Graesser (Eds.), Metacognition in educational theory and practice (pp. 277-304). Mahwah: Lawrence Erlbaum.

Winne, P. H., Zhou, M., \& Egan, R. (2011). Designing assessments of self-regulated learning. In G. Schraw \& D. Robinson (Eds.), Assessment of higher order thinking skills (pp. 89-118) IAP.

Wise, A., \& Scwartz, B. (2017). Visions of CSCL: Eight provocations for the future of the field. International Journal of Computer-Supported Collaborative Learning, 12, 423-467.

Wolters, C. A. (2011). Regulation of motivation: Contextual and social aspects. Teachers College Record, 113(2), $265-283$.

Publisher's note Springer Nature remains neutral with regard to jurisdictional claims in published maps and institutional affiliations.

\section{Affiliations}

\section{Jonna Malmberg ${ }^{1} \cdot$ Eetu Haataja $^{1} \cdot$ Tapio Seppänen $^{1} \cdot$ Sanna Järvelä ${ }^{1}$}

Eetu Haataja

eetu.haataja@oulu.fi

Tapio Seppänen

sanna.jarvela@oulu.fi

Sanna Järvelä

tapio.seppanen@oulu.fi

1 University of Oulu, Oulu, Finland 